\title{
The Sense of Quality of Life Among the Elderly in the Open Protection Centres of the Elderly (KAPI) During the Economic Crisis
}

\author{
Zacharias Dermatis $^{1}$, Athanasia Konstantinopoulou ${ }^{1}$, Athina Lazakidou ${ }^{1} \&$ Athanasios Anastasiou $^{1}$ \\ ${ }^{1}$ University of Peloponnese, Department of Economics, Digital Health Applications and Health Economics Analytics \\ Laboratory, Tripolis, Greece \\ Correspondence: Zacharias Dermatis, University of Peloponnese, Department of Economics, Digital Health \\ Applications and Health Economics Analytics Laboratory, Tripolis, Greece.
}

Received: April 1, 2019

Accepted: May 6, 2019

Available online: May 14, 2019

doi:10.11114/aef.v6i4.4268

URL: https://doi.org/10.11114/aef.v6i4.4268

\begin{abstract}
Surveys in the field of health sociology have repeatedly shown that people belonging to low socio-economic groups face health problems and live less than people belonging to high socio-economic groups. The purpose of the current survey is to investigate the socio-economic indicators that affect the health level of the elderly. A number of questionnaires were distributed to the elderly in a number of Open Protection Centres of the Elderly (KAPI) in the country. A total of 897 questionnaires were filled in. The data was processed using the IBM SPSS Statistics v. 23. Regarding the existence of correlations between economic characteristics and the sense of the quality of life of the elderly, it was established that people with economic autonomy and highest annual income perceive their quality of life as being superior compared to those lacking economic autonomy and lower annual income. There is almost complete coincidence of the research findings with the theoretical approaches of the literature survey. Specifically, there is an apparently stronger proportional relationship of the "Sense of Quality of Life" with the Health Characteristics of the respondents and a less proportional relationship of the "Sense of Quality of Life" with the Economic Characteristics of the respondents.
\end{abstract}

Keywords: health, economic factors, elderly, sense of quality of life, open protection centres of the elderly

\section{Introduction}

The purpose of the present survey is to investigate the socio-economic indicators that affect the health level of the elderly, while the individual objectives of the thesis are: To record the current profile of the elderly in the country's Open Centres of Elderly Care, as it is in the period of the economic crisis, to explore the perception of the elderly about the impact of the economic crisis on their health and quality of life, to assess the factors that affect the quality of their life and to investigate the degree of correlation between socio-economic indicators and the quality of their life.

\section{Socio-Economic Indicators in the Health of the Elderly}

Surveys in the field of health sociology have repeatedly shown that people belonging to low socio-economic groups face health problems and live less than people belonging to high socio-economic groups (Machenbach et al., 1997). Huisman et al. conducted a survey with people aged 65 and over to investigate the relationship between their socio-economic situation and mortality (Huisman et al., 2004). This study has made a significant contribution to the literature on inequalities and mortality, and stresses the importance of examining the health of elderly in public health policy and actions. This is an issue of increasing importance given the aging of the population in developed countries because of the increase in life expectancy and the poor health of people over 60 years of age.

The aim of the Grundy \& Holt survey was to identify the most commonly used indicators of socio-economic status (social class, educational level, income, household financial resources, poverty indicators, housing and car ownership) (Grundy \& Holt, 2001). The best pair of variables, according to the used criteria in this survey, was the educational level or the social class combined with an indicator of poverty.

According to other studies, differences in health due to their socio-economic situation are lesser for young adults and increase while age increases (House et al., 1990, House et al., 1994 and Beckett, 2000). The main explanation for the existence of health inequalities for the elderly is the lowering of the levels of health at the later stages of their life which 
may be due to psychological factors contributing to poor health (House et al., 1994) such as: lack of social relationships and social support, changes in the elders psychological mood such as reduced sense of sovereignty, optimism, sense of control and self-esteem or increased levels of anger and hostility, long term and acute anxiety in occupation including anxiety of marginalization of classism and other phenomena related to the social distribution of power and resources (Lantz et al., 1998). Another explanation of health inequalities is also due to the physical deterioration of the aging body (Hayflick, 1998), which plays a key role in identifying old age (House et al., 2005; Mirowsky \& Ross, 2005).

Furthermore, education is related to the increasing divergence in the health status of the elderly (Mirowsky \& Ross, 2005; Dupre, 2008; Mirowsky \&.Ross, 2008; Willson et al., 2007; DiPrete \& Eirich; O'Rand \& Hamil-Luker, 2005; Ross \& Wu, 1996). Long-term economic distress seems to have cumulative effects on the health of older people (McDonough \& Berglund, 2003; Benzeval \& Judge, 2001; Lynch et al., 1997).

\section{The Effect of Economic Crisis}

In accordance with the above interdisciplinary and holistic approaches and at the same time with the biological factors, socio-economic, psychological and environmental factors have a significant impact on the health of the general population. In particular, the adverse effects of the economic crisis on Greece are expected to negatively impact on health indicators such as life expectancy, morbidity, mental health, mortality, suicide, domestic violence, etc. In addition, the economic crisis strengthens social inequalities, poverty and social exclusion, and there are also serious problems in funding health systems. Reducing private and public spending has a negative impact on access to health care services, and the functioning of public health care units is burdened due to increased demand (Patrick \& Erickson, 1993).

In addition, it is expected that in future people will become more dependent on social pensions and public benefits as a result of the high increase in unemployment rates, which is expected to exacerbate Greece's fiscal ratios. It is important to note that current demographic developments in Greece are projected to lead to an increase in the demand for use of health services due to the increasing needs of the elderly, especially as regards diseases of deterioration and chronic health problems. In addition, it will have significant negative effects on social protection issues as well as on public finances in Greece. Finally, the aging population implies a relative labour shortage, reduced productivity ratios, and reduced returns on capital, which also reduce the country's assets.

\section{Scope of Research}

The scope of the current survey is to investigate the socio-economic indicators that affect the health level of the elderly. The specific objectives of the survey are:

1. Record the current profile of the elderly in the country's Open Centres of Elderly Care, as it is shaped during the economic crisis.

2. Investigate the perception of the elderly about the impact of the economic crisis on their health and sense of quality of life.

3. Assess the factors that shape the quality of life of the elderly.

4. Investigate the degree of correlation between socio-economic indicators and the quality of life of elderly.

According to Carone \& Costello, the importance of such surveys lies in the fact that they can make a significant contribution to addressing uncertainty in the demographic and budgetary forecasts as well as the complex challenges of policies in health care and long-term care pensions (Carone \& Costello, 2006).

Finally, these studies are a valuable tool for facilitating difficult political debates on issues related to the quality of life and health of the population and how it is influenced by socio-economic factors.

\section{Research Methodology}

The quantitative method of data was used for the current survey, which allows a systematic collection of objective numerical data and its presentation in numerical form for the purposes of statistical analysis (Mantzoukas, 2007) based on a typical sequence of research stages.

Data collection was conducted in the country's Open Centres of Elderly Care. The survey period was started in the Open Centre of Elderly Care of the Municipality of Patras in March 2015 and was completed in the Open Protection Centres of the Elderly (KAPI) Municipality of Rhodes in July 2016.

The questionnaires were filled in on a voluntary basis by the elderly. The questionnaires were accompanied by a letter stating clearly the purpose of the survey.

The completed questionnaires were introduced into the electronic database to be processed and analysed. Data processing was carried out with the IBM SPSS Statistics v. 23, where the results were plotted and all the inductive 
statistical checks were performed.

A dummy variable named "Sense of Quality of Life" (SQL) was used as a mean value of three variables Quality of Life, Enjoyment of Life and Feeling of Happiness, in order to investigate its correlation with the Health Characteristics and the Economic Characteristics of the elderly during the economic crisis. Spearman correlation and linear regression were used to examine these correlations.

In order to obtain valid and scientific results, a representative sample of the studied population was collected (Bellali \& Papazoglou, 2004), from a total of 897 questionnaires, so that the results and conclusions drawn from them and related to this population could be generalized.

\section{Results}

Table 1 presents the elements of the "Sense of Quality of Life" of the participants in the survey. In the question about their Quality of Life, the elderly respondents replied in their highest percentage of $44.8 \%$ that it is good and $7.2 \%$ very good. Also, $37.3 \%$ of respondents said that it is moderate, while only $8.4 \%$ and $2.2 \%$ said, that it is bad and very bad, respectively. It was also noticed that $53.4 \%$ fully agreed that they enjoy their life, while $12.2 \%$ disagreed. Still, $51.6 \%$ fully agreed that they felt happy for much of the time, while $14.2 \%$ disagreed.

Table 1. Elements consisting the dummy variable "Sense of Quality of Life" of elderly of the survey.

\begin{tabular}{lrrrrrr}
\hline \multirow{2}{*}{ Level of feeling } & \multicolumn{2}{c}{ Quality of Life } & \multicolumn{2}{c}{ Enjoyment of Life } & \multicolumn{2}{c}{ Feeling of Happiness } \\
\cline { 2 - 7 } & Frequency & Percent & Frequency & Percent & Frequency & Percent \\
\hline Very high level & 65 & 7.2 & 79 & 8.8 & 106 & 11.8 \\
High level & 402 & 44.8 & 400 & 44.6 & 357 & 39.8 \\
Medium level & 335 & 37.3 & 308 & 34.3 & 307 & 34.2 \\
Low level & 75 & 8.4 & 91 & 10.1 & 105 & 11.7 \\
Very low level & 20 & 2.2 & 19 & 2.1 & 22 & 2.5 \\
\hline Total & 897 & 100.0 & 897 & 100.0 & 897 & 100.0 \\
\hline
\end{tabular}

Table 2 presents the results of the descriptive statistics on the economic characteristics of the participants and in particular on the existence of economic self-reliance and on the amount of annual income. $75.1 \%$ of the survey population said they had financial self-reliance. With regard to the annual income of the research population, $42.6 \%$ had an average annual income from 6.001 to $12000 €, 24 \%$ from 12.001 to $24000 €, 21.9 \%$, from 0 to $6000 €, 4.2 \%$ from $24,000 €$ and upwards, while $7.4 \%$ had no income.

Table 2. Elements consisting the economic characteristics of elderly.

\begin{tabular}{|c|c|c|c|c|c|}
\hline \multicolumn{3}{|c|}{ Self-Financed } & \multicolumn{3}{|c|}{ Annual Income } \\
\hline Yes or No & Frequency & Percent & $€$ & Frequency & Percent \\
\hline \multirow{3}{*}{ Yes } & \multirow{3}{*}{674} & \multirow{3}{*}{75.1} & $>24,000$ & 132 & 14.7 \\
\hline & & & $12,001-24,000$ & 386 & 43.0 \\
\hline & & & $6,001-12,000$ & 210 & 23.4 \\
\hline \multirow{2}{*}{ No } & \multirow{2}{*}{223} & \multirow{2}{*}{24.9} & $1-6,000$ & 128 & 14.3 \\
\hline & & & 0 & 41 & 4.6 \\
\hline Total & 897 & 100,0 & Total & 897 & 100,0 \\
\hline
\end{tabular}

Table 3 presents the results of descriptive statistics on the health characteristics of participants, and in particular on the existence of physical energy, and whether they consider themselves healthy enough to have some kind of activity. Regarding the general health situation, $56.8 \%$ believed that they had some physical energy, while $19.5 \%$ disagreed. Moreover, $57.7 \%$ believed that they were healthy to some extent in order to have some kind of activity, while $18.9 \%$ disagreed with this view. 
Table 3. Elements consisting the health characteristics of elderly.

\begin{tabular}{lrrrr}
\hline \multirow{2}{*}{ Level of feeling } & \multicolumn{2}{c}{ Physical Energy } & \multicolumn{3}{c}{ Healthy enough } \\
\cline { 2 - 5 } & Frequency & Percent & Frequency & Percent \\
\hline Very high level & 111 & 12.4 & 132 & 14.7 \\
High level & 317 & 35.3 & 386 & 43.0 \\
Medium level & 309 & 34.4 & 210 & 23.4 \\
Low level & 118 & 13.2 & 128 & 14.3 \\
Very low level & 42 & 4.7 & 41 & 4.6 \\
\hline Total & 897 & 100.0 & 897 & 100.0 \\
\hline
\end{tabular}

Table 4 shows the Spearman correlation between the economic characteristics and the "Sense of Quality of Life" of the elderly. The results came from using the SPSS software. It is noted that economic self-reliance is slightly linearly and positively correlated with the "Sense of Quality of Life" of the elderly $(r=0.218, p<0.05)$. In particular, the assumption is that financially self-sufficient people perceive their quality of life as being superior in all aspects compared to those who do not have financial self-reliance. It is also noted that annual income is slightly linearly and positively correlated with the "Sense of Quality of Life" of the elderly $(r=0.265, p<0.05)$. In particular, the assumption is that the highest income earners perceive their quality of life as being superior in all aspects compared to those with lower income.

Table 4. Spearman correlations of "Sense of Quality of Life" of elderly with each element of the economic characteristics of elderly.

\begin{tabular}{|c|c|c|}
\hline Dependent Dummy Variable & $\begin{array}{c}\text { Independent } \\
\text { Variable }\end{array}$ & Spearman Correlation Value \\
\hline Sense of Quality of Life & Financial Independence & $\begin{array}{c}0.218 \\
(\mathrm{p}=0.000)\end{array}$ \\
\hline Sense of Quality of Life & Annual Income & $\begin{array}{c}0.265 \\
(\mathrm{p}=0.000)\end{array}$ \\
\hline \multicolumn{3}{|c|}{$\begin{array}{l}\text { Table } 5 \text { shows the Spearman correlations between characteristics and the "Sense of Quality of Life" of the elderly. The } \\
\text { results came from using the SPSS program. It is noticed that the existence of good natural energy strongly correlates } \\
\text { linearly and positively with the "Sense of Quality of Life" of the elderly ( } \mathrm{r}=0.628, \mathrm{p}<0.05 \text { ). Specifically, the } \\
\text { hypothesis is that people with good physical condition perceive their quality of life as being superior in all aspects, } \\
\text { compared to those who are not fit. It was also found that the health that allows the activity strongly correlates linearly } \\
\text { and positively with the "Sense of Quality of Life" of the elderly ( } \mathrm{r}=0.545, \mathrm{p}<0.05 \text { ). In particular, the hypothesis is } \\
\text { confirming that health-wise people perceive their quality of life as being superior in all aspects than those who do not } \\
\text { have a health-conscious activity. }\end{array}$} \\
\hline \multicolumn{3}{|c|}{$\begin{array}{l}\text { Table 5. Spearman correlations of "Sense of Quality of Life" of elderly with each element of the health characteristics } \\
\text { of elderly. }\end{array}$} \\
\hline Dependent Dummy Variable & $\begin{array}{c}\text { Independent } \\
\text { Variable }\end{array}$ & Spearman Correlation Value \\
\hline Sense of Quality of Life & Physical Energy & $\begin{array}{c}0.628 \\
(\mathrm{p}=0.000)\end{array}$ \\
\hline Sense of Quality of Life & Healthy enough & $\begin{array}{c}0.545 \\
(\mathrm{p}=0.000)\end{array}$ \\
\hline
\end{tabular}

Finally, the dependent dummy variable named "Sense of Quality of Life" (SQL) was associated with the group consisting of the independent variables Economic Autonomy (EA) and Annual Income (AI) as Economic Characteristics, as well as with the group consisting of the independent variables Physical Energy (PE) and Health Sensitivity (HS) as Health Characteristics.

\section{Discussion}

Regarding the existence of correlations between economic characteristics and aspects of the quality of life of the elderly, it is established that: a) elderly with economic autonomy perceive their quality of life as being superior in all aspects compared to those with lack in economic autonomy; b) elderly with higher annual income better perceive their quality of life as being superior in all aspects compared to those that have a lower level of annual income. Regarding the existence of correlations between health characteristics and aspects of the quality of life of older people, it is established 
that: a) elderly with good health which allows them to have activity, perceive their quality of life as being superior in all aspects compared to those who do not b) elderly with a good physical condition perceive their quality of life as being superior in all aspects than those who do not have a good physical condition.

From the results of the linear regression, which demonstrates the correlations, it follows that "Sense of Quality of Life" (values 1 to 5) is related to Economic Autonomy (integer values 1 to 2) and Annual Income (integer values 1 to 5) as variables of Economic Characteristics, with the following relationship (Eq. 1 \&Table 6):

$$
\mathrm{SQL}=0.264(\mathrm{EA})+0.176(\mathrm{AI})+1.663
$$

Table 6. Constants of linear regression correlating the "Sense of Quality of Life" of elderly with the elements of the economic characteristics of elderly.

\begin{tabular}{cccc}
\hline Dependent Dummy Variable & $\begin{array}{c}\text { Independent } \\
\text { Variable }\end{array}$ & $\begin{array}{c}\text { Coefficient of Linear } \\
\text { Regression }\end{array}$ & $\begin{array}{c}\text { Constant of Linear } \\
\text { Regression }\end{array}$ \\
\hline \multirow{2}{*}{ Sense of Quality of Life } & Financial Independence & $\begin{array}{c}0.264 \\
(\mathrm{p}=0.000)\end{array}$ & $\begin{array}{c}1.663 \\
(\mathrm{p}=0.000)\end{array}$ \\
\cline { 2 - 3 } & Annual Income & $\begin{array}{c}0.176 \\
(\mathrm{p}=0.000)\end{array}$ & \\
\hline
\end{tabular}

Additionally, from the results of the linear regression, it follows that "Sense of Quality of Life" (values 1 to 5) is related to Physical Energy (integer values 1 to 5) and Health Sensitivity (integer values 1 to 5) as Health Characteristics variables, with the following relationship (Eq. 2 \&Table 7):

$$
\mathrm{SQL}=0.387(\mathrm{PE})+0.186(\mathrm{HS})+1.047
$$

Table 7. Constants of linear regression correlating the "Sense of Quality of Life" of elderly with the elements of the health characteristics of elderly.

\begin{tabular}{cccc}
\hline Dependent Dummy Variable & $\begin{array}{c}\text { Independent } \\
\text { Variable }\end{array}$ & $\begin{array}{c}\text { Coefficient of Linear } \\
\text { Regression }\end{array}$ & $\begin{array}{c}\text { Constant of Linear } \\
\text { Regression }\end{array}$ \\
\hline \multirow{2}{*}{ Sense of Quality of Life } & Physical Energy & $\begin{array}{c}0.387 \\
(\mathrm{p}=0.000)\end{array}$ & $\begin{array}{c}1.047 \\
(\mathrm{p}=0.000)\end{array}$ \\
\cline { 2 - 3 } & Healthy enough & $\begin{array}{c}0.186 \\
(\mathrm{p}=0.000)\end{array}$ & \\
\hline
\end{tabular}

From the above it is obviously more pronounced the proportional relation of the "Sense of Quality of Life" with the Health Characteristics of the respondents and less pronounced the proportional relationship of the "Sense of Quality of Life" with the Economic Characteristics of the respondents. It is also noted that the findings of these correlations through linear regression are fully consistent with previous Spearman correlations.

Given the usefulness of health research and in particular, the identification of health problems for the elderly, it is proposed to expand:

- the research in other countries, notably the European Union, with a view to the wider collection and evaluation of data and the comparative presentation of data and surveys in the Member States of the Union.

- the search for the elderly in places other than the Open Protection Centres of the Elderly (KAPI), such as elderly people living in nursing homes or hospitalized at home.

\section{Conclusion}

Regarding the existence of correlations between health characteristics and the sense of the quality of life of the elderly, it is established that: a) the hypothesis that the health-wise ones, that had some kind of activity, perceived their quality of life as being superior in all aspects compared to those who did not, is verified (b) those who had a good physical condition perceived their quality of life as being superior in all aspects than those who did not had a good physical condition.

From the application of linear regression, it is obvious that there is an apparently stronger proportional relationship of the "Sense of Quality of Life" with the Health Characteristics of the respondents and a less proportional relationship of the "Sense of Quality of Life" with the Economic Characteristics of the respondents.

It has been observed that the almost complete coincidence of research findings and their statistical analysis with the theoretical approaches of the reported literature.

Obviously, the quality and accuracy of research depends to a great extent on the sincerity of the respondents and their size. 


\section{References}

Beckett, M. (2000). Health Inequalities in Later Life: An Artifact of Mortality Selection?. Journal of Health and Social Behavior, 41, 106 -119. https://doi.org/10.2307/2676363

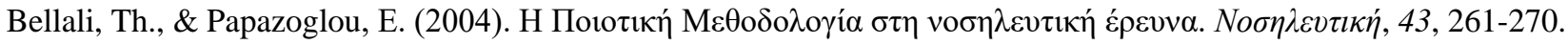

Benzeval, M., \& Judge, K. (2001). Income and Health: The Time Dimension. Social Science and Medicine, 52, $1371-90$. https://doi.org/10.1016/S0277-9536(00)00244-6

Carone, G., \& Costello, D. (2006). Can Europe afford to grow old?. Finance and Development, 43(3), 1-9.

DiPrete, T. A., \& Eirich, G. M. (2006). Cumulative Advantage as a Mechanism for Inequality: A Review of Theoretical and Empirical Developments. Annual Review of Sociology, 32, 271-297. https://doi.org/10.1146/annurev.soc.32.061604.123127

Dupre, M. E. (2008). Educational Differences in Health Risks and Illness over the Life Course: A Test of Cumulative Disadvantage Theory. Social Science Research, 37, 1253-1266. https://doi.org/10.1016/j.ssresearch.2008.05.007

Grundy, E., \& Holt, G. (2001). The socioeconomic status of older adults: How should we measure it in studies of health inequalities?. J Epidemiol Community Health, 55, 895-904. https://doi.org/10.1136/jech.55.12.895

Hayflick, L. (1998). How and Why We Age. Experimental Gerontology, 33, 639-653. https://doi.org/10.1016/S0531-5565(98)00023-0

House et al. (1990). Age, Socioeconomic Status, and Health. The Milbank Quarterly, 68, 383-411. https://doi.org/10.2307/3350111

House, J. S., Lantz, P. M., \& Herd, P. (2005). Continuity and Change in the Social Stratification of Aging and Health over the Life Course: Evidence from a Nationally Representative Longitudinal Study from 1986 to $2001 / 2002$ (Americans' Changing Lives Study). Journals of Gerontology Series B Psychological Sciences and Social Sciences, 60, 15-26. https://doi.org/10.1093/geronb/60.Special_Issue_2.S15

House, J. S., Lepkowski, J. M., Kinney, A. M., Mero, R. P., Kessler, R. C., \& Herzog, A. R. (1994). The Social Stratification of Aging and Health, Journal of Health and Social Behavior, 35, 213-234. https://doi.org/10.2307/2137277

Huisman, M., Kunst, A. E, \& Andersen, O. (2004). Socioeconomic inequalities in mortality among elderly people in 11 European populations. J Epidemiol Community Health, 58, 468-75. https://doi.org/10.1136/jech.2003.010496

Lantz, P. M., House, J. S., Lepkowski, J. M., Williams, D. R., Mero, R. P., \& Chen, J. (1998). Socioeconomic factors, health behaviors, and mortality: results from a nationally representative prospective study of U.S. adults. JAMA., 279, 1703-1708. https://doi.org/10.1001/jama.279.21.1703

Lynch, J. W., Kaplan, G. A., \& Salonen, J. T. (1997). Why do poor people behave poorly? Variation in adult health behaviours and psychosocial characteristics by stages of the socioeconomic lifecourse. Soc. Sci. Med, 44, 809-819. https://doi.org/10.1016/S0277-9536(96)00191-8

Machenbach, J. P., Kunst, A. E., \& Cavelaars, A. E. (1997). Socioeconomic inequalities in morbidity and mortality in Western Europe. The EU Working Group on Socioeconomic Inequalities in Health. Lancet, 349, $1655-9$. https://doi.org/10.1016/S0140-6736(96)07226-1

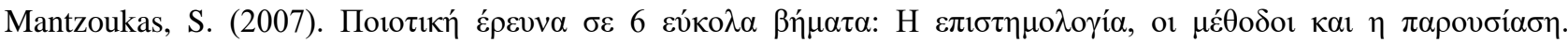

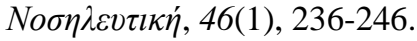

McDonough, P., \& Berglund, P. (2003). Histories of Poverty and Self-Rated Health Trajectories. Journal of Health and Social Behavior, 44, 198-214. https://doi.org/10.2307/1519808

Mirowsky, J., \& Ross, C. E. (2008). Education and Self-Rated Health: Cumulative Advantage and Its Rising Importance. Research on Aging, 30, 93-122. https://doi.org/10.1177/0164027507309649

Mirowsky, J., \& Ross, C. E. (2005). Education, Cumulative Advantage and Health. Aging International, $30(1), 27-62$. https://doi.org/10.1007/BF02681006

O'Rand, A. M., \& Hamil-Luker, J. (2005). Processes of Cumulative Adversity: Childhood Disadvantage and Increased Risk of Heart Attack across the Life Course. Journals of Gerontology Series B: Psychological Sciences and Social Sciences, 60B, S117-S124. https://doi.org/10.1093/geronb/60.Special_Issue_2.S117

Patrick, B., \& Erickson, B., D. (1993). Health status and health policy. Allocating Resources to Health Care. Oxford University Press, Oxford. 
Ross, C. E., \& Wu, C. L.(1996). Education, Age, and the Cumulative Advantage in Health. Journal of Health and Social Behavior, 37, 104-120. https://doi.org/10.2307/2137234

Willson, A. E., Shuey, K. M., \& Elder, G. H. J. (2007). Cumulative Advantage Processes as Mechanisms of Inequality in Life Course Health. American Journal of Sociology, 112, 1886-1924. https://doi.org/10.1086/512712

\section{Copyrights}

Copyright for this article is retained by the author(s), with first publication rights granted to the journal.

This is an open-access article distributed under the terms and conditions of the Creative Commons Attribution license which permits unrestricted use, distribution, and reproduction in any medium, provided the original work is properly cited. 